Tohoku J. Exp. Med., 2003, 200, 67-73

\title{
Estimation of Daily Mercury Intake from Seafood in Japanese Women: Akita Cross-Sectional Study
}

\author{
Yoko Imasaki, Mineshi Sakamoto, ${ }^{1}$ Kunihiko Nakai, ${ }^{2}$ Tomoko Oka, ${ }^{2}$ \\ Miwako Dakeishi, ${ }^{3}$ Toyoto Iwata, ${ }^{3}$ Hiroshi Satoh $^{2}$ and Katsuyuki \\ Murata $^{3}$ \\ Environmental Health Department, Ministry of the Environment, Tokyo 100 \\ -8975 , \\ ${ }^{1}$ Department of Epidemiology, National Institute for Minamata Disease, \\ Minamata 867-0008, \\ ${ }^{2}$ Environmental Health Sciences, Tohoku University Graduate School of \\ Medicine, Sendai 980-8575, and \\ ${ }^{3}$ Environmental Health Sciences, Department of Social Medicine, Akita \\ University School of Medicine, Akita 010-8543
}

Iwasaki, Y., Sakamoto, M., Nakai, K., Oka, T., Dakeishi, M., Iwata, T., Satoh, H. and Murata, K. Estimation of Daily Mercury Intake from Seafood in Japanese Women: Akita Cross-Sectional Study. Tohoku J. Exp. Med., 2003, 200 (2), 67-73 — We estimated daily mercury intakes from seafood in 154 mothers residing in several cities and towns in Akita, Japan, to address the relationships between the reference dose ( $R f D$ of $0.1 \mu \mathrm{g} / \mathrm{kg}$ body weight per day, derived by US EPA) and daily mercury intakes, combined with hair mercury levels. The frequency and volume of seafood ingested by them were examined using a food frequency questionnaire (FFQ) with 25 kinds of full-scale pictures including fish and shellfish items. Hair mercury concentrations in the mothers were also determined. The geometric means in the mothers were 15.3 (2.65-48.4) $\mu \mathrm{g} /$ day for daily mercury intakes from seafood, calculated on the basis of the references on mercury contents, and $1.73(0.49-5.82) \mu \mathrm{g} / \mathrm{g}$ for hair mercury concentrations. The daily mercury intake was significantly correlated with hair mercury concentrations (Spearman rank correlation coefficient $r_{s}=0.335, p<0.001$ ). No significant differences in mercury intakes were found either between mothers residing in fishing and non-fishing areas or between those in cities and towns $(p>0.05)$. Assuming the methylmercury content rate of $75 \%$ in seafood mercury and body weight of $55 \mathrm{~kg}$, the mothers were estimated to ingest methylmercury of $0.21 \mu \mathrm{g} /$ $\mathrm{kg}$ body weight per day. It is suggested that daily mercury intakes, calculated by the $\mathrm{FFQ}$, reflect hair mercury levels, and there is no interregional difference in the daily mercury intake unless any special circumstance exists. Daily methylmercury intake in more than $90 \%$ of Japanese women may exceed the $R f D$, and it

Received April 28, 2003; revision accepted for publication June 9, 2003.

Address for reprints: Katsuyuki Murata, Environmental Health Sciences, Department of Social Medicine,

Akita University School of Medicine, 1-1-1 Hondo, Akita 010-8543, Japan.

e-mail: winestem@ @med.akita-u.ac.jp 
therefore seems to be far from the present state of Japanese dietary lives. daily mercury intake; seafood; food frequency questionnaire; reference dose; methylmercury

(C) 2003 Tohoku University Medical Press

Humans are mainly exposed to methylmercury from seafood and freshwater fish, and poisoning incidents have also involved grain treated with this substance as fungicide (Kurland et al. 1959; Bakir et al. 1973). After the first epidemic in Minamata, Japan, where many fishermen and their families developed methylmercury poisoning in the 1950s, the disease was dubbed Minamata disease (Igata 1993). The cause was fish contaminated by drainage, containing methylmercury, from a chemical production plant. But, the main problem today is the widespread occurrence of methylmercury in fish and marine mammals, thus exposing human populations with a high fish intake and especially those who consume from high levels of the food chains. Since the risk to children from dietary methylmercury exposure is unclear, current advisories on fish consumption issued by national and state authorities aim mainly at pregnant women or women of reproductive age groups (United Nations Environment Programme Chemicals 2002).

Risk assessment of methylmercury exposure is an important public-health consideration as a basis for preventive efforts (National Research Council 2000). From data on the Iraqi poisoning episode, Cox et al. (1989) estimated the maternal hair mercury concentration of approximately $10 \mu \mathrm{g} / \mathrm{g}$ as a safe level for prenatal mercury exposure. Taking into account uncertainty factors, the US Environmental Protection Agency (1997) then proposed a safe level (reference dose, $R f D$ ) for methylmercury exposure at $0.1 \mu \mathrm{g} / \mathrm{kg}$ body weight per day. However, since little information has been developed concerning the daily mercury intake in Japan (Shishido and Suzuki 1974), the significance of the $R f D$ remains unclear. For this reason, we estimated the daily mercury intake from seafood in Japanese women by using a food frequency questionnaire (FFQ), to address the relationships between the RfD and daily mercury intakes, combined with hair mercury concentrations.

\section{MATERIALS AND METHODS}

This research was carried out as a part of the Akita cross-sectional study on the effects of prenatal methylmercury exposure on child neurodevelopment. Prior to this, the study protocol was approved by the ethical review committee at the Akita University School of Medicine. The nature of the procedures used in the present study was explained to the parents at eight elementary schools, and mothers and the 7-yearold children were invited for this study during the period of July-September in 2002. The children at 7 years of age were chosen in accordance with the preceding study on the risk assessment of methylmercury exposure (Murata et al. 1999). The participating subjects, from whom informed consent was obtained, were 154 mothers at $35.7 \pm 4.2$ (range, $25 \sim 48$ ) years of age, and the children, residing in two cities and three towns of Akita Prefecture, Japan. Four of the eight schools, which the children went to, were located in near the fishing harbor. Hair samples were obtained, by cutting strands of hair close to the scalp, from the occipital area in all mothers and children. The hair length was generally about $10 \mathrm{~cm}$, ranged from 1 to $30 \mathrm{~cm}$. And, total mercury in aliquots of dried hair samples (15 to $20 \mathrm{mg})$, cut into small pieces $(<2$ $\mathrm{mm}$ ) with scissors after being washed well with detergent and rinsed two times with acetone, was determined by the cold vapor atomic 
absorption spectrophotometry method at the National Institute for Minamata Disease (Akagi and Nishimura 1991).

Detailed survey on the frequency and volume of seafood ingested in a year was conducted by a trained interviewer at the schools or civic centers where examinations on child neurodevelopment were also done, showing 25 kinds of full-scale pictures including fish, shellfish and seaweed items (e.g., tuna, swordfish, skipjack tuna, codfish, flatfish, mackerel, sardine, sea bream, whale, salmon, eel, crab, prawn, octopus, squid, oyster, sea urchin, fish paste, shellfish, seaweed, and etc.) to each mother, based upon the FFQ (Nakai et al. 2003), i.e., a modified version of Date et al. (1996). Then, the total mercury intake from seafood $(\mu \mathrm{g} /$ year) was estimated on the basis of the previous references on mercury concentrations in seafood (Yamamoto et al. 1990; Nakagawa et al. 1997), and daily mercury intake was calculated dividing by 365 days. Also, questionnaires on hairdyed and artificial hair waving were collected from the mothers.

The significance of the relationships between daily mercury intake and hair mercury concentrations was analyzed by the Spearman rank correlation coefficient $\left(r_{s}\right)$. The Wilcoxon signed rank test was used to evaluate the difference in the hair mercury concentration between the mother and child. The two-way analysis of variance by the SS model of type II was available for evaluation of the interregional differences (i.e., between cities and towns, and between fishing and non-fishing areas). All analyses were performed using the Statistical Package for the Biosciences (SPBS V9.5) (Murata and Yano 2002).

\section{RESULTS}

The geometric mean of daily mercury intakes, calculated from the 154 mothers, was 15.3 (range, $2.65 \sim 48.4) \mu \mathrm{g} /$ day. The geometric means of hair mercury levels were 1.73 (range, 0 . 49 5.82) $\mu \mathrm{g} / \mathrm{g}$ in the mothers and 1.64 (range, 0.
45 6.32) $\mu \mathrm{g} / \mathrm{g}$ in the children, but there was no significant difference in the hair mercury concentration between the mother and child $(p>0$. $05)$. The daily mercury intake was significantly correlated with hair mercury concentrations in the mothers and children (Fig. 1). Also, maternal hair mercury was significantly correlated with child's hair mercury $\left(r_{s}=0.291, p<\right.$ 0.001). On the other hand, no significant differences in the daily mercury intake or hair mercury concentrations were found either between mothers residing in cities and towns or between those in fishing and non-fishing areas (Table 1 and Fig. 1). There were no significant correlations between their ages and either the daily mercury intake or hair mercury concentrations $\left(r_{s}=-0.011 \sim 0.013, p>0.05\right)$.

As the average and standard deviation (S.D.) values of body weight were 54.6 and $9.55 \mathrm{~kg}$ in 16353 women aged 30-44 years, residing in Akita Prefecture (2002's data of the Akita Prefectural Center of Health Care), body weight of $55 \mathrm{~kg}$ for mothers was used to convert daily ingested dose $(\mu \mathrm{g} /$ day) to that per body weight $(\mu \mathrm{g} / \mathrm{kg}$ body weight per day). Assuming the methylmercury content rate of $75 \%$ in seafood mercury (Notification of the Environmental Hygiene Bureau, Ministry of Health and Welfare on July 23rd, 1973), the mothers were speculated to ingest methylmercury of $0.21 \mu \mathrm{g} /$ $\mathrm{kg}$ body weight per day (geometric mean), as shown in Table 2.

A significant difference in the hair mercury level was seen between the 47 mothers with artificial hair waving (mean \pm S.D., $1.70 \pm 0.95$ $\mu \mathrm{g} / \mathrm{g})$ and 107 mothers without $(2.10 \pm 0.98 \mu \mathrm{g} /$ $\mathrm{g})$; this difference was statistically significant $(p=0.011)$ when controlling for daily mercury intake. On the other hand, the hair mercury level did not differ significantly between the 120 mothers with dyed hair $(1.95 \pm 1.03 \mu \mathrm{g} / \mathrm{g})$ and 34 mothers without $(2.07 \pm 0.78 \mu \mathrm{g} / \mathrm{g})$.

\section{DISCUSSION}

This study showed that the daily dietary 

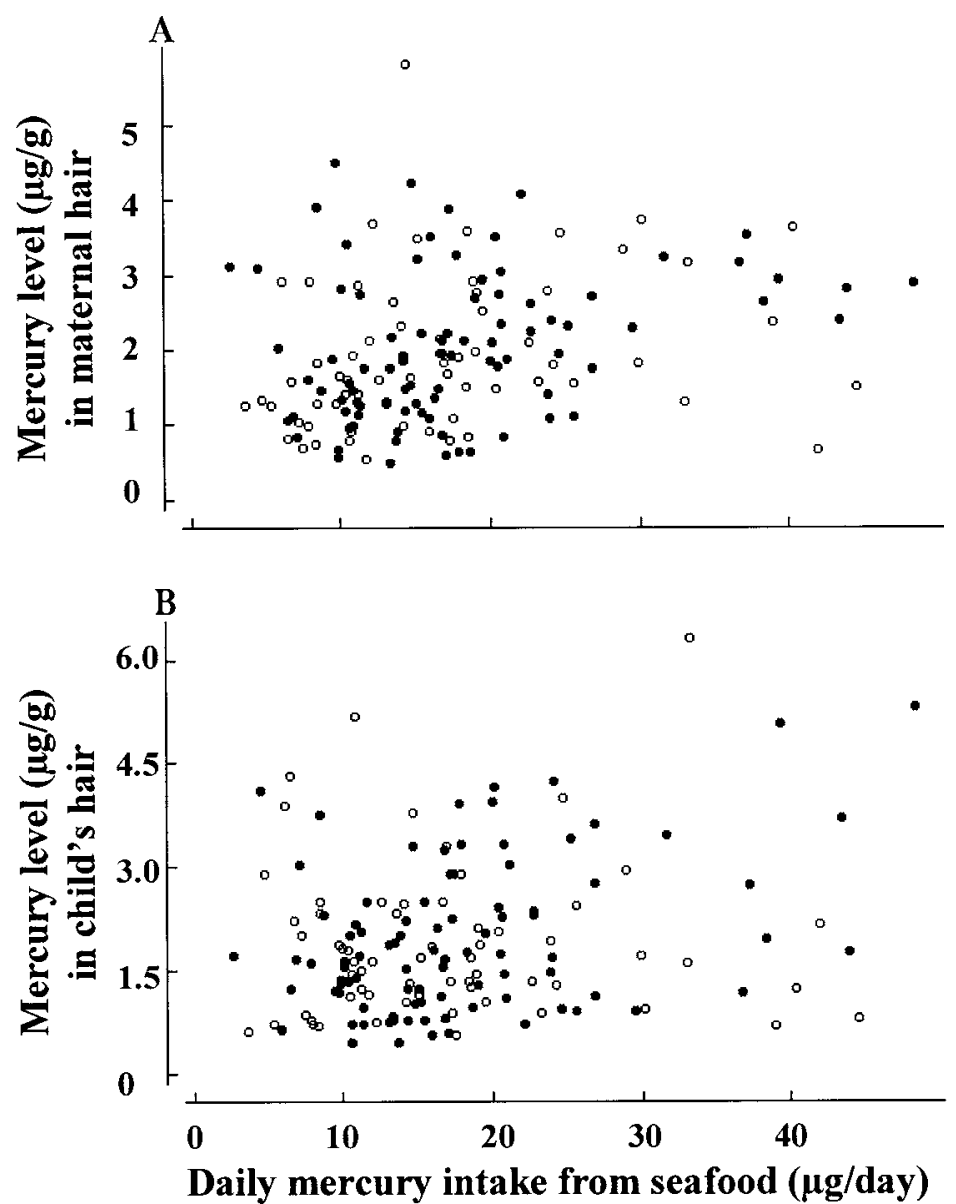

Fig. 1. Relationships between the daily mercury intake and hair mercury concentrations in 154 mothers and the children in Akita, Japan. $r_{s}, \bigcirc$ and - indicate the Spearman rank correlation coefficient, and subjects residing in fishing and non-fishing areas, respectively.

A: Mercury level $(\mu \mathrm{g} / \mathrm{g})$ in maternal hair, $r_{s}=0.335, p<0.001$.

B: Mercury level $(\mu \mathrm{g} / \mathrm{g})$ in child's hair, $r_{s}=0.161, p<0.047$.

TABLE 1. Residence-specific mercury concentrations and daily mercury intakes in 154 mothers and the children in Akita, Japan number of samples, mean \pm S.D.)

\begin{tabular}{lrl}
\hline & Non-fishing areas & Fishing areas \\
\hline Mother's hair $(\mu g / g)^{\mathrm{a}}$ & & \\
Cities & $56,1.92 \pm 0.90$ & $26,1.90 \pm 1.22$ \\
Towns & $35,2.17 \pm 1.07$ & $37,1.95 \pm 0.87$ \\
Child's hair $(\mu g / g)^{\mathrm{b}}$ & $56,1.99 \pm 1.21$ & \\
Cities & $35,1.90 \pm 0.94$ & $26,1.76 \pm 0.98$ \\
Towns & $56,19.0 \pm 9.9$ & $37,1.96 \pm 1.24$ \\
Mother's daily intake $(\mu g /$ day) & \\
Cities & $35,15.9 \pm 7.0$ & $26,17.0 \pm 10.4$ \\
Towns & $37,17.0 \pm 9.0$ \\
\hline
\end{tabular}

${ }^{\mathrm{a}} F=0.567(p=0.638) ;{ }^{\mathrm{b}} F=0.263(p=0.852) ;{ }^{\mathrm{c}} F=0.875(p=0.455)$. 
TABLE 2. Distribution of daily methylmercury intakes ( $\mu \mathrm{g} / \mathrm{kg}$ body weight per day), estimated from 154 mothers in Akita, Japan, under the assumption that body weight of mother was $55 \mathrm{~kg}$, and methylmercury-mercury ratio in seafood was 0.75

\begin{tabular}{ccc}
\hline Daily intake & Number of mothers & Proportion (\%) \\
\hline$\leqq 0.1$ & 13 & 8.4 \\
$\leqq 0.2$ & 55 & 35.7 \\
$\leqq 0.3$ & 50 & 32.5 \\
$\leqq 0.4$ & 19 & 12.3 \\
$\leqq 0.5$ & 6 & 3.9 \\
$>0.5$ & 11 & 7.2 \\
\hline
\end{tabular}

intake of mercury (median $15.9 \mu \mathrm{g} /$ day), examined by one interviewer using the $\mathrm{FFQ}$, was significantly associated with hair mercury concentrations, especially in the mothers (median $1.8 \mu \mathrm{g} / \mathrm{g}$ ). Shishido and Suzuki (1974) measured the contents of total and organic mercury from dishes of five daily diets, and the daily intakes ranged from 3.3 to $70.9 \mu \mathrm{g}$ for total mercury and from 2.7 to $70.0 \mu \mathrm{g}$ for organic mercury. According to the Faroe Islands Prospective Study, an average total mercury intake per person over age 14 could be calculated to be about $36 \mu \mathrm{g}$ /day based on the data from the questionnaire study and mercury concentrations in whale and cod, and maternal hair mercury concentrations in the cohort showed a median of $4.5 \mu \mathrm{g} / \mathrm{g}$ (Grandjean et al. 1992; Weihe and Grandjean 1994). Concerning an interference of recall bias (that is, an inevitable problem on the FFQ), another study of the FFQ with 122 food items has reported that the correlation coefficients between nutrients estimated by the first and second tests conducted at an interval of one week (i.e., reproducibility) ranged from 0.64 for vegetable protein to 0.78 for calcium (Date et al. 1996). Therefore, this method with the FFQ is suggested to provide a useful approach for estimating daily mercury intake.

In the mothers of the present study, the daily methylmercury intake was calculated to be $0.21 \mu \mathrm{g} / \mathrm{kg}$ body weight per day, under the assumption that the methylmercury content was $75 \%$ of seafood mercury. Probably, children would also ingest a similar level of methylmercury, because there was no significant difference in the hair mercury level between the mother and child. The US Environmental Protection Agency (1997) described that the dose of $1.1 \mu \mathrm{g} /$ $\mathrm{kg}$ body weight per day was the total daily quantity of methylmercury that was ingested by a $60 \mathrm{~kg}$ individual to maintain a hair concentration of $11 \mu \mathrm{g} / \mathrm{g}$. Despite the different calculation process, this closely resembles our outcome in the relation of daily methylmercury intake to hair mercury concentration. If the above assumption is correct, daily methylmercury intake in more than $90 \%$ of Japanese women and children may exceed the RfD of $0.1 \mu \mathrm{g} / \mathrm{kg}$ body weight per day (US Environmental Protection Agency 1997; National Research Council 2000). For that reason, the RfD does not seem to be suitable for Japanese dietary lives, especially with respect to the achievement of the object. For the establishment of a reference dose of the daily methylmercury intake for Japanese, risk assessment of methylmercury exposure should be carried out in a Japanese cohort, like the Seychelles Child Development Study (Davidson et al. 1998) and the Faroe Islands Prospective Study (Grandjean et al. 1997). Moreover, additional study is required to determine the methylmercury concentration contained in each of fish, shellfish and seaweed directly.

Hair mercury concentrations in the mothers of Akita were below the safe limit (10 $\mu \mathrm{g} / \mathrm{g}$ ) of the International Programme on Chemical Safety (1990), and the mothers with artificial hair waving had lower hair mercury concentrations than did those without. Our study population consisted of 82 mothers in cities and 72 mothers in towns. Also, 666137 persons resided in cities and 517870 resided in towns in Akita Prefecture in March 2001, which were almost similar to our study population with 
regard of the residential distribution. Yasutake et al. (2003) examined total mercury levels of 1666 female hair samples collected from five districts of Japan, presenting that the geometric mean was $1.43 \mu \mathrm{g} / \mathrm{g}$, and that the geometric mean in each district varied from 1.23 to $2.50 \mu \mathrm{g} / \mathrm{g}$. Similar mercury levels in Japan have been reported by some researchers (Wakisaka et al. 1990; Sakamoto et al. 1993). In this way, although these hair mercury levels may have been somewhat underestimated due to artificial hair waving (Yamamoto and Suzuki 1978; Yasutake et al. 2003), our data appear to reflect current mean values in Japanese women.

Any significant difference in the daily mercury intake or maternal hair mercury level was not observed either between fishing and non-fishing areas or between cities and towns in Akita Prefecture (Table 1), although hair mercury levels in Chiba were significantly elevated when compared to those in Minamata, Kumamoto, Wakayama and Tottori (Yasutake et al. 2003); while, the authors did not describe any reason. In the time of the epidemic outbreak of methylmercury poisoning in Minamata, fishermen used to barter fish and shellfish for rice in the territorial society, independent of monetary economy. However, according to the rumor that intake of fish caught from Minamata Bay caused a peculiar disease, most of people except fishermen and their families did hardly eat fish contaminated by methylmercury, and patients with Minamata disease increased mainly in fishing villages (Doi 1994). In contrast, we can purchase all types of commodities including fish and shellfish everywhere because of infiltration of monetary economy and development of the distribution system. Thus, the absence of interregional differences in the daily mercury intake may have been attributable to the equalization of dietary lives.

In conclusion, the daily intake of dietary methylmercury from seafood in Japanese women was estimated to be between 0.09 and
$0.53 \mu \mathrm{g} / \mathrm{kg}$ body weight per day (i.e., 5 and 95 percentiles). The actual intake may exceed the above estimate, because the current content rate of methylmercury in seafood mercury is suggested to be more than 0.75 (Kehrig et al. 1998). Anyway, since they are changeable through various circumstances, a continuous monitoring of methylmercury is necessary.

\section{Acknowledgments}

We thank Prof. Philippe Grandjean for his valuable suggestions, and Dr. Satoshi Terui and the Akita Prefectural Education Board for their cooperation of collecting the study population. This study was supported by a grant from Japan Ministry of the Environment.

\section{References}

Akagi, H. \& Nishimura, H. (1991) Speciation of mercury in the environment. In: Advances in Mercury Toxicology, edited by T. Suzuki, N. Imura \& T.W. Clarkson, Plenum Press, New York, pp. 53-76.

Bakir, F., Damluji, S.F., Amin-Zaki, L., Murtadha, M., Khalidi, A., Al-Rawi, N.Y., Tikriti, S., Dhahir, H.I., Clarkson, T.W., Smith, J.C. \& Doherty, R.A. (1973) Methylmercury poisoning in Iraq. Science, 181, 230-241.

Cox, C., Clarkson, T.W., Marsh, D.O., Amin-Zaki, L., Tikriti, S. \& Myers, G.G. (1989) Doseresponse analysis of infants prenatally exposed to methyl mercury: An application of a single compartment model to single-strand hair analysis. Environ. Res., 49, 318-332.

Date, C., Yamaguchi, M. \& Tanaka, H. (1996) Development of a food frequency questionnaire in Japan. J. Epidemiol., 6, S131-S136.

Davidson, P.W., Myers, G.J., Cox, C., Axtell, C., Shamlaye C., Sloane-Reeves, J., Cernichiari, E., Needham, L., Choi, A., Wang, Y., Berlin, M. \& Clarkson, T.W. (1998) Effects of prenatal and postnatal methylmercury exposure from fish consumption on neurodevelopment: outcomes at 66 months of age in the Seychelles Child Development Study. JAMA, 280, 701-707.

Doi, R. (1994) Minamata disease. In: Toxicology Today: from Toxicology to Biomedical Sciences, edited by H. Satoh, Kinpodo Publisher, Kyoto, pp. 93-108.

Grandjean, P., Weihe, P., Jørgensen, P.J., Clarkson, 
T., Cernichiari, E. \& Vider $\phi, \quad$ T. (1992) Impact of maternal seafood diet on fetal exposure to mercury, selenium, and lead. Arch. Environ. Health, 47, 185-195.

Grandjean, P., Weihe, P., White, R.F., Debes, F., Araki, S., Yokoyama, K., Murata, K., Sфrensen, N., Dahl, R. \& Jфrgensen, P.J. (1997) Cognitive deficit in 7-year-old children with prenatal exposure to methylmercury. Neurotoxicol. Teratol., 19, 417-428.

Igata, A. (1993) Epidemiological and clinical features of Minamata disease. Environ. Res., 63, 157-169.

International Programme on Chemical Safety (1990) Methylmercury (Environmental Health Criteria 101). World Health Organisation, Geneva.

Kehrig, H.A., Malm, O., Akagi, H., Guimaraes, J.R. \& Torres, J.P. (1998) Methylmercury in fish and hair samples from the Balbina Feservoir, Brazilian Amazon. Environ. Res., 77, 84-90.

Kurland, L.T., Faro, S.N. \& Siedler, H. (1959) Minamata disease: the outbreak of a neurologic disorder in Minamata, Japan, and its relationship to the ingestion of seafood contaminated by mercuric compounds. World Neurol., 1, 370-395.

Murata, K., Weihe, P., Renzoni, A., Debes, F., Vasconcelos, R., Zino, R., Araki, S., Jørgensen, P.J., White, R.F. \& Grandjean, P. (1999) Delayed evoked potentials in children exposed to methylmercury from seafood. Neurotoxicol. Teratol., 21, 343-348.

Murata, K. \& Yano, E. (2002) Medical Statistics for Evidence-Based Medicine with SPBS User's Guide. Nankodo Publisher, Tokyo.

Nakagawa, R., Yumita, Y. \& Hiromoto, M. (1997) Total mercury intake from fish and shellfish. Chemosphere, 35, 2909-2913.

Nakai, K., Sakamoto, M., Murata, K., Oka, T., Suzuki, K., Okamura, K., Hosokawa, T., Mori, Y. \& Satoh, H. (2003) Effects of perinatal exposures to methylmercury and environmentally persistent organic pollutants on neurobehavioral development in Japanese children: a protocol for the prospective cohort study. In: Proceedings of NIMD FORUM 2002: The Study of Fetal Methylmercury Exposure and Children Development. National Institute for Minamata Disease, Minamata, pp. 51-58.

National Research Council (2000) Toxicological Effects of Methylmercury. National Academy Press, Washington, DC.

Sakamoto, M., Nakano, A., Akagi, H., Kitano, T. \& Futatsuka, M. (1993) Difference by sex and age of mercury concentration in red blood cells. Jpn. J. Hyg., 48, 911-919.

Shishido, S. \& Suzuki, T. (1974) Estimation of daily intake of inorganic or organic mercury via diet. Tohoku J. Exp. Med., 114, 369-377.

United Nations Environment Programme Chemicals (2002) Global Mercury Assessment. UNEP Chemicals, Geneva.

US Environmental Protection Agency (1997) Mercury Study for Congress. Volume V: Health Effects of Mercury and Mercury Compounds. EPA-452/R-97-007. EPA, Triangle Prak.

Wakisaka, I., Yanagihashi, T., Sato, M. \& Nakano, A. (1990) Factors contributing to the difference of hair mercury concentrations between the sexes. Jpn. J. Hyg., 45, 654-664.

Weihe, P. \& Grandjean, P. (1994) Sources and magnitude of mercury exposure in the Faroe Islands: overall design of the cohort study. In: Proceedings of the International Symposium on Assessment of Environmental Pollution and Health Effects from Methylmercury. National Institute for Minamata Disease, Minamata, pp. 112-126.

Yamamoto, I., Matsuda K. \& Sato, C. (1990) Contents of Heavy Metals in Seafood along the Coast of Hokkaido. Hokkaido Institute of Public Health, Sapporo.

Yamamoto, R. \& Suzuki, T. (1978) Effects of artificial hair-waving on hair mercury values. Int. Arch. Occup. Environ. Health, 42, 1-9.

Yasutake, A., Matsumoto, M., Yamaguchi, M. \& Hachiya, N. (2003) Current hair mercury levels in Japanese: survey in five districts. Tohoku J. Exp. Med., 199, 161-169. 